\title{
Addressing non-economic loss and damage associated with climatic events: Cases of Japan and Bangladesh
}

\author{
Yohei Chiba a*, Sivapuram Venkata Rama Krishna Prabhakar a, and Md. Atikul Islam ${ }^{\mathrm{b}}$ \\ a Institute for Global Environmental Strategies (IGES), Hayama, 240-0115, Japan \\ b Khulna University, Khulna-9208, Bangladesh \\ * Corresponding author. Email: yoheichiba@gmail.com
}

\section{ABSTRACT}

Non-economic loss and damage (NELD) could constitute a major proportion of the total loss and damage caused by any climate-related disasters. Despite this, most NELD has not been well measured and reported in most post-disaster reports and databases and has often not been given the attention it deserves in most disaster risk assessments and risk reduction interventions. Issues include a lack of proper recognition among the stakeholders engaged in disaster risk reduction and climate change adaptation of the value that society attaches to NELD, and a lack of simple methods to identify, prioritize and measure NELD. Keeping these barriers in view, this research aimed to develop an assessment framework to identify and prioritize NELD in key vulnerable sectors and make policy recommendations for addressing NELD. In this paper, results from case studies conducted in Japan and Bangladesh, two of the five project countries, are presented for a better understanding on this subject. The analytic hierarchy process (AHP) was used to identify and prioritize key NELD caused by climate-related disasters and to identify important risk reduction practices that could address NELD. The findings show that mental health disorders can be one common and important NELD in both Bangladesh and Japan despite their contrasting developmental situations. Inaccessible sanitation and waterborne diseases were Bangladesh-specific NELD, while poor risk governance and risk communication between local governments and communities were Japan-specific NELD.

\section{KEYWORDS}

Climate change adaptation, Climaterelated disasters, Community, Disaster risk reduction, Loss and damage, Mental health, Non-economic loss and damage

\section{DOI}

https://doi.org/10.30852/sb.2019.740

\section{DATES}

Received: 26 May 2018

Published (online): 3 September 2019

Published (PDF): 7 December 2019

\section{HIGHLIGHTS}

» This paper identified non-economic loss and damage (NELD) such as loss of health, and loss of social, cultural, and environmental assets as important for achieving long-term and sustainable risk reduction. The disaster impact assessments and post-disaster needs assessments (PDNAs) that are being conducted must include NELD in order to inform the follow-up risk reduction interventions.

» The paper identified that NELD has not been well considered in disaster risk reduction and climate change adaptation interventions and that NELD is difficult to adequately understand, identify and estimate due to the complex pathways through which various different types of NELD manifest.

» This paper demonstrated the application of an analytic hierarchy process (AHP) for identifying and prioritizing key types of NELD and risk reduction solutions for addressing NELD caused by climate-related disasters.

» The paper highlighted that issues such as mental health disorders can be a common type of NELD in Bangladesh and Japan. There is a need to strengthen the existing risk reduction measures addressing mental health issues, and interventions should be evaluated for their ability to address NELD. 


\section{INTRODUCTION}

Loss and damage (L\&D) caused by climate-related disasters is one of the most crucial challenges in the context of climate change. In particular, non-economic loss and damage (NELD), such as loss of human functions, social and cultural assets, and environmental assets, has not been well considered in climate change adaptation (CCA) and disaster risk reduction (DRR)related decision-making. Recognizing the importance of this issue, the sixteenth session of the Conference of the Parties (COP16) under the United Nations Framework Convention on Climate Change (UNFCCC) suggested the necessity to address L\&D, and COP19 established the Warsaw International Mechanism (WIM) to tackle L\&D (Decision 2/CP.19) in 2013, which was further strengthened by the Paris Agreement in 2015. The WIM highlights NELD as a key area of its work with a five-year rolling work plan, and its Executive Committee established an expert group on NELD to enhance data on and knowledge of NELD (UNFCCC, 2017). Further, the recently concluded COP24 in Katowice, Poland emphasized the need to address loss and damage in global stock-take rules and transparency rules.

Despite these efforts, the countermeasures to address NELD are still lacking at the national level because of limited understanding on the subject and limited means to identify, measure and estimate, as well as mitigate NELD (UNFCCC, 2013; UNFCCC, 2014; UNFCCC, 2017). NELD has also not been sufficiently reported in most post-disaster reports and databases (Swiss Re, 2013; Chiba, Shaw, \& Prabhakar, 2017). The low attention paid to NELD can result in significant underestimation of actual disaster losses, leading to insufficient and suboptimal investments in recovery, suboptimal DRR and CCA decision-making, and a decrease in community resilience to climatic disasters (IPCC, 2014; Morrissey \& Oliver-Smith, 2013; Chiba, Prabhakar, Islam, \& Akber, 2018).

Keeping the above background in view, this research aimed to understand NELD caused by recent past major climate-related disasters and develop an assessment framework to identify and prioritize NELD. This paper, in particular, provides a comparative analysis of key NELD in Bangladesh and Japan (Chiba \& Prabhakar, 2017; Chiba et al., 2018). The findings will contribute to enhanced understanding and data collection of key NELD under the UNFCCC process and at the national and local levels.

\section{METHODOLOGY}

This study involved country-level expert consultations, participatory approaches such as community-level focus group discussion (FGDs), questionnaire surveys, and the analytic hierarchy process (AHP) to identify and prioritize key NELD caused by climate-related disasters in two study locations in Bangladesh and Japan. The process helped to identify important issues in NELD, and important risk reduction practices that could address NELD from the perspective of the affected local communities and local government officials (Chiba \& Prabhakar, 2017; Chiba et al., 2018). The study in two countries helped to obtain an understanding of contrasts and commonalities in NELD under two different developmental situations that are elaborated in this paper.

\subsection{AHP-based approach}

The study applied community-based participatory approach with the analytic hierarchy process (AHP) to examine key types of NELD caused by climate-related disasters in Bangladesh and Japan (Chiba \& Prabhakar, 2017; Chiba et al., 2018). The AHP is a multi-criteria decision-making tool that can be used to solve complex decision problems (Saaty, 1990). It has been widely applied to group decision-making, as well as questionnaire surveys, in many disciplines; and is based on a multi-level hierarchical structure consisting of the goal, criteria, sub-criteria (i.e., indicators), and alternatives (i.e. practices). It uses a set of pairwise comparisons to derive the weights of importance for each element at each level, using a scale of absolute judgements that represents how much more one element dominates the other.

In this study, elements of AHP analysis for NELD consisted of decision criteria, indicators and alternatives (i.e. risk reduction practices) for addressing NELD (Chiba \& Prabhakar, 2017; Chiba et al., 2018). The AHP elements were identified, evaluated and prioritized by following sequential steps: literature review; expert and community consultations; and questionnaire surveys. Comprehensive literature review in the context of DRR

\begin{tabular}{|l|l|l|}
\hline & Bangladesh & Japan \\
\hline $\begin{array}{l}\text { Number of } \\
\text { respondents from } \\
\text { local communities }\end{array}$ & 247 & 175 \\
\hline $\begin{array}{l}\text { Number of } \\
\text { respondents from } \\
\text { local government } \\
\text { officials }\end{array}$ & 26 & 22 \\
\hline $\begin{array}{l}\text { Who undertook } \\
\text { fieldwork }\end{array}$ & NELD expert & NELD expert \\
\hline $\begin{array}{l}\text { When it was } \\
\text { undertaken }\end{array}$ & $\begin{array}{l}\text { November - } \\
\text { December 2016 }\end{array}$ & $\begin{array}{l}\text { October - } \\
\text { November 2016 }\end{array}$ \\
\hline Language used & Bengali & Japanese \\
\hline
\end{tabular}

TABLE 1. Questionnaire surveys in Bangladesh and Japan (Source: Chiba \& Prabhakar, 2017; Chiba et al., 2018). 
and CCA was conducted to understand NELD, expert consultations assessed the suitability of proposed NELDrelated elements identified from the literature in each country context, and community consultations through focus group discussions then narrowed the scope of NELD-related elements and identified key NELD-related elements from the affected community perspective. Subsequently, structured questionnaire surveys helped prioritize key NELD-related elements from a broader sample of affected local communities and local government officials (Table 1). The questionnaires consisted of key criteria, indicators and practices examined by expert and community consultations.

\subsection{Study location}

\subsubsection{Bangladesh: Koyra Upazila, Khulna}

Koyra Upazila in the Khulna district of Bangladesh was selected as the study location for several reasons, including serious L\&D from Cyclone Aila in 2009, and the rich social, cultural and environmental assets that were exposed to the cyclone (Chiba et al., 2018). Koyra has a total population of 193,931 , with $50.9 \%$ female population and a population density of 861 per sq. km, growing at a rate of $1.7 \%$ per annum (Bangladesh Bureau of Statistics [BBS], 2011). The majority of households depend on agriculture, fishing, forestry and labour for their livelihoods. The annual rainfall ranges from 1,500 $\mathrm{mm}$ to $2,000 \mathrm{~mm}$, with about $70 \%$ of the total rainfall in the monsoon season.

Cyclone Aila in 2009 is one of the most severe disasters that Bangladesh has suffered during recent years, followed by Cyclone Sidr which happened in 2007 (Chiba et al., 2018). It affected an estimated 3.90 million people in 11 coastal districts in Bangladesh. The cyclone severely affected Koyra killing 57 people (United Nations Development Programme [UNDP], 2009). Approximately 300,000 people were affected, and thousands of houses were completely $(49,000)$ or partially $(27,000)$ destroyed. Significant L\&D, especially in the farming and fishing sectors, were reported due to inundation of paddy fields, shrimp farms (fish ponds), and sweet fish ponds with saline water. About 40,000 people had migrated from Koyra by October 2009 (European Commission Humanitarian Aid [ECHO], 2009).

\subsubsection{Japan: Nachikatsuura Town, Wakayama}

Nachikatsuura Town, Wakayama Prefecture in Japan, was chosen as the study site for several reasons such as the severity of L\&D from Typhoon Talas, the 12th typhoon of the season in 2011, as well as the vulnerability of the rural small municipality with limited capacity and social, cultural and environmental assets that were exposed to NELD (Chiba \& Prabhakar, 2017). Nachikatsuura is located in the southeast part of Wakayama on the Kii Peninsula, bordering the Pacific Ocean, and has $88 \%$ of the total area under forests (Ministry of Agriculture, Forestry and Fisheries [MAFF], 2015). It is also a tourist destination with UNESCO-designated World Heritage Sites, including Kumano Nachi Taisha Grand Shrine and Nachi Falls. The town lies in a warm-temperate zone, has an average annual precipitation of more than $2,000 \mathrm{~mm}$, with the highest recorded rainfall of 4,000 $\mathrm{mm}$ in 2011 (Nachikatsuura Town, 2013). On average, the town is hit by 3.2 typhoons every year (Japan Meteorological Agency [JMA], 2017). It has a total population of 15,946 (male: 7,405 ; female: 8,541 ) with a household count of 8,046 as of February 2017 (Nachikatsuura Town, 2017). With 39\% of the population above 65 years, a large proportion of whom are single; this town is ranked 9th in Wakayama in terms of proportion of aged population (Wakayama Prefecture, 2016).

Typhoon Talas in 2011 is one of the most severe disasters that Nachikatsuura has suffered during recent years, with the highest casualties in Wakayama Prefecture (Chiba \& Prabhakar, 2017). The main causes of damage were debris flow and river flooding from the heavy rainfall that accompanied the typhoon. As a result, 2,410 households were affected, 29 people died (including one missing), 14,458 people were evacuated ( $91 \%$ of the town

\begin{tabular}{|c|c|c|c|}
\hline Rank & Criteria & Indicators & Practices \\
\hline \multicolumn{4}{|c|}{ Community members } \\
\hline 1 & Compliance with societal value & Inaccessible sanitation & DRR policy and planning \\
\hline 2 & Relevance to DRR/CCA policy and planning & Waterborne diseases & DRR policy and planning \\
\hline 3 & Measurability and verifiability & Mental health disorder & Disaster compensation \\
\hline \multicolumn{4}{|c|}{ Government officials } \\
\hline 1 & Compliance with societal value & Waterborne diseases & Disaster compensation \\
\hline 2 & Relevance to DRR/CCA policy and planning & Inaccessible sanitation & Cyclone shelter policy \\
\hline 3 & Measurability and verifiability & Schools discontinued & Cyclone shelter policy \\
\hline
\end{tabular}

TABLE 2. List of NELD-related elements prioritized by community members and government officials in Koyra (Source: Chiba, 2018). 


\begin{tabular}{|l|l|l|l|}
\hline Rank & Criteria & Indicators & Practices \\
\hline \multicolumn{2}{|l|}{ Community members } & $\begin{array}{l}\text { Less collaboration between local } \\
\text { government and community }\end{array}$ & Emergency shelters \\
\hline 1 & Compliance with societal value & $\begin{array}{l}\text { Less community participation in } \\
\text { decision-making }\end{array}$ & DRR policy and planning \\
\hline 2 & Relevance to DRR/CCA policy and planning & Disaster compensation \\
\hline Government officials & Mental health disorder & DRR policy and planning \\
\hline 1 & Compliance with societal value & Mental health disorder & Emergency shelters \\
\hline 2 & Relevance to DRR/CCA policy and planning & $\begin{array}{l}\text { Less collaboration between local } \\
\text { government and community }\end{array}$ & Disaster compensation \\
\hline 3 & Measurability and verifiability & Chronic diseases & \\
\hline
\end{tabular}

TABLE 3. List of NELD-related elements prioritized by community members and government officials in Nachikatsuura (Source: Chiba \& Prabhakar, 2017).

population), 103 houses were completely destroyed, and 17 public facilities were affected. The economic damage totalled JPY2,283 million (Nachikatsuura Town, 2013).

\section{RESULTS AND DISCUSSION}

\subsection{Bangladesh}

\subsubsection{Community perspective}

Table 2 shows the overall results of NELD-related elements prioritized through questionnaire surveys to community members in Koyra. "Compliance with societal value" was a principal criterion for decision-making. The community members put more emphasis on water and sanitation indicators including "inaccessible sanitation" and "waterborne diseases", and a health-related indicator of "mental health disorder". They, in turn, determined the "DRR policy and planning" as the most effective risk reduction practice to address NELD.

\subsubsection{Local government perspective}

As shown in Table 2, "Relevance to DRR/CCA policy and planning" was considered the most important criterion by local government officers for identifying appropriate indicators and practices. The government officers also identified "waterborne diseases", "inaccessible sanitation," and "school discontinued" as important indicators for assessing the effectiveness of interventions and that "DRR policy and planning" as the most effective practice to address NELD.

\subsection{Japan}

\subsubsection{Community perspective}

Table 3 presents the overall results of NELD-related elements prioritized through questionnaire surveys to community members in Nachikatsuura. Similar to the case of Bangladesh, "compliance with societal values" appears to be the dominant criterion for decision-making, and community members prioritized local governance indicators such as "less collaboration of local government with local communities", "less participation of community in decision-making", and "mental health disorder" as important indicators for identifying effective practices for addressing NELD. The community members prioritized "emergency shelters" to secure safe locations for local communities to be the most effective risk reduction practice to address NELD. The focus on emergency shelters indicates the short-term nature of the NELD impacts, which was not the case in Bangladesh, where long-term impacts of NELD appeared to have dominated decision-making.

\subsubsection{Local government perspective}

Similar to the community perspective, "compliance with societal value" was considered most important by local government officials. The indicators of "mental health disorder", "less collaboration of local government with local communities" and "chronic diseases" were the three most prioritized indicators and, in contrast to the community perspective, "DRR policy and planning" was the most effective risk reduction practice to address NELD, indicating the long-term view taken by government officials.

\subsection{NELD and development nexus}

Comparing results between Bangladesh and Japan may provide some insights into the association between the developmental state of the country and opinions of respondents in terms of NELD indicators and practices. The results indicate that both Bangladesh and Japan placed high importance for addressing the issue of mental health disorder (Table 4). Different characteristics of these countries in terms of NELD could also be 


\begin{tabular}{|l|l|l|c|c|c|}
\hline \multicolumn{2}{|l|}{ NELD } & \multicolumn{2}{|l|}{ Bangladesh: Koyra } & \multicolumn{2}{l|}{ Japan: Nachikatsuura } \\
\hline \multirow{2}{*}{ Impact area } & Indicators & Community & Gov't & Community & Gov't \\
\hline \multirow{2}{*}{ Health } & Mental health disorder & $\bullet$ & & $\bullet$ & $\bullet$ \\
\cline { 2 - 6 } & Chronic diseases & & & & $\bullet$ \\
\hline $\begin{array}{l}\text { Water \& } \\
\text { sanitation }\end{array}$ & Inaccessible sanitation & $\bullet$ & $\bullet$ & & \\
\cline { 2 - 6 } & Waterborne diseases & $\bullet$ & $\bullet$ & & \\
\hline Education & Schools discontinued & & $\bullet$ & & $\bullet$ \\
\hline \multirow{2}{*}{$\begin{array}{l}\text { Local } \\
\text { governance }\end{array}$} & Less collaboration & & & & $\bullet$ \\
\cline { 2 - 6 }
\end{tabular}

TABLE 4. Comparison of top three NELD in this study (Note: Gov't = Local government officials, $\bullet=$ prioritized. Source: Authors).

found. In the case of Bangladesh, issues such as inaccessible sanitation, and waterborne diseases took precedence in discussions with community members and government officials. This is in line with the significant challenge that developing countries, in particular, are facing after cyclones due to the breakdown of water and sanitation systems and the dearth of safe drinking water (Haque et al., 2012). On the other hand, Japan's case has highlighted challenges in local risk governance raising the need for close coordination and communication with community associations, voluntary organizations, and volunteer groups, and for establishing communication channels to seek opinions and consensus-building with communities.

\section{CONCLUSION}

The study intended to understand NELD caused by recent past major climate-related disasters and developed a methodological framework to identify and prioritize NELD and important practices to address NELD. The cases of Bangladesh and Japan were presented. The AHP was applied to identify and prioritize key types of NELD caused by climate-related disasters and to find important risk reduction practices that could address NELD.

For Koyra, from the community perspective, the study identified "compliance with societal value" as an important criterion, "inaccessible sanitation", "waterborne diseases" and "mental health disorder" as important indicators, and "DRR policy and planning" as an important risk reduction practice. On the other hand, for Nachikatsuura, the study specified "compliance with societal value", "less collaboration of local government with local communities", "less participation of the community in decision-making", "mental health disorder", and "emergency shelter" as essential NELD elements. The results indicate that both Bangladesh and Japan placed high importance on addressing the issue of mental health disorder. Bangladesh identified serious issues of inaccessible sanitation and waterborne diseases, while Japan highlighted challenges in local risk governance in terms of communication between local government and communities. There is a need for these prioritized NELD to be incorporated into the post-disaster needs assessments (PDNAs), and post-disaster impact assessments conducted in both countries. Local governments in both countries have damage assessment formats that are filled in during disasters, and that ensure the prioritized NELD are incorporated into these formats for regular data collection and use for risk reduction decision making. The findings will lead to enhancing the UNFCCC process in terms of NELD-related data and knowledge.

\section{ACKNOWLEDGEMENT}

We gratefully acknowledge several researchers, government officials, non-governmental organizations and community members who participated in this project directly and indirectly by providing valuable time, experiences and expertise, including being part of the workshops, consultations, and surveys conducted in this project. The authors are grateful that part of this research was supported by the Environment Research and Technology Development Fund (2-1801) of the Environmental Restoration and Conservation Agency of Japan.

\section{REFERENCES}

Bangladesh Bureau of Statistics, Statistics and Informatics Division, Ministry of Planning, Government of the People's Republic of Bangladesh. (2011). Report of Household Income and Expenditure Survey 2010. Dhaka: BBS.

Chiba, Y., \& Prabhakar, S. (2017). Priority Practices for 
Addressing Non-economic Loss and Damage caused by Typhoons in Japan: Case Study of Nachikatsuura Town. Kanagawa: Institute for Global Environmental Strategies (IGES).

Chiba, Y., Shaw, R., \& Prabhakar, S. (2017). Climate change-related non-economic loss and damage in Bangladesh and Japan. International Journal of Climate Change Strategies and Management, 9(2), 166-183.

Chiba, Y., Prabhakar, S. V. R. K., Islam, M. A., \& Akber, M. A. (2018). Priority practices for addressing non-economic loss and damages caused by cyclones in Bangladesh: Case study of Koyra. International Journal of Disaster Resilience in the Built Environment, 9(4/5), 333-347.

European Commission Humanitarian Aid. (2009). In-depth Recovery Needs Assessment of Cyclone Aila Affected Areas. Brussels: ECHO.

Haque, U., Hashizume, M., Kolivras, K. N., Overgaard, H. J., Das, B., \& Yamamoto, T. (2012). Reduced death rates from cyclones in Bangladesh: What more needs to be done?. Bulletin of the World Health Organization, $90(2), 150-156$

Intergovernmental Panel on Climate Change. (2014). Climate Change 2014: Impacts, Adaptation, and Vulnerability. Part A: Global and Sectoral Aspects. Contribution of Working Group II to the Fifth Assessment Report of the Intergovernmental Panel on Climate Change. Cambridge, United Kingdom and New York, NY, USA: Cambridge University Press.

Japan Meteorological Agency. (2017). Average numbers of typhoons. Retrieved April 4, 2017 from http:// www.data.jma.go.jp/fcd/yoho/typhoon/statistics/ average/average.html

Ministry of Agriculture, Forestry and Fisheries. (2015). Nachikatsuura Town, Wakayama. Retrieved February 9, 2017 from http://www.machimura.maff.go.jp/ machi/contents/30/421/details.html

Morrissey, J., \& Oliver-Smith, A. (2013). Perspectives on Non-Economic Loss and Damage: Understanding values at risk from climate change. (K. Warner \& $\mathrm{S}$. Kreft, Eds.). Bonn: Loss and Damage in Vulnerable Countries Initiative, United Nations University.

Nachikatsuura Town. (2013). Kii Peninsula Flood Disaster. Wakayama: Nachikatsuura Town.

Nachikatsuura Town. (2017). Nachikatsuura Town. Retrieved February 9, 2017 from https://www.town.nachikatsuura.wakayama.jp/forms/top/top.aspx

Saaty, T. L. (1990). How to make a decision: The analytic hierarchy process. European Journal of Operational Research, 48(1), 9-26.

Swiss Re. (2013). Natural catastrophes and man-made disasters in 2012: A year of extreme weather events in the US. Zurich: Swiss Re.
United Nations Development Programme. (2009). Field Visit Report on Selected AILA affected areas. Dhaka: UNDP Bangladesh.

United Nations Framework Convention on Climate Change. (2013). Non-economic losses in the context of the work programme on loss and damage. Bonn: UNFCCC, United Nations.

United Nations Framework Convention on Climate Change. (2014). Report of the Executive Committee of the Warsaw International Mechanism for Loss and Damage associated with Climate Change Impacts. Bonn: UNFCCC, United Nations.

United Nations Framework Convention on Climate Change. (2017). Report of the Executive Committee of the Warsaw International Mechanism for Loss and Damage associated with Climate Change Impacts. Bonn: UNFCCC, United Nations.

Wakayama Prefecture. (2016). The status of aging population in Wakayama Prefecture. Wakayama: Wakayama Prefecture. 